\title{
Effects of Arbuscular Mycorrhizal Fungi on Root Growth and Architecture of Tulip Gesneriana
}

\author{
Hongna $\mathrm{Mu}^{1}$, Lei Fan ${ }^{1}$, Shaohua $\mathrm{Zhu}^{1} \&$ Taoze $\mathrm{Sun}^{1}$ \\ ${ }^{1}$ College of Horticulture and Gardening, Yangtze University, Jingzhou, 434025, China \\ Correspondence: Taoze Sun, College of Horticulture and Gardening, Yangtze University, Jingzhou, 434025, China. \\ E-mail: suntaoze@yangtzeu.edu.cn
}

Received: November 3, 2020 Accepted: November 16, 2020 Online Published: December 9, 2020

\begin{abstract}
Arbuscular mycorrhizal fungi(AMF) can promote the absorption of soil water and mineral nutrients, improve photosynthesis, and make host attain higher quality finally by establishing symbiotic relationship between AMF and host root. To improve Tulip gesneriana quality have practical meaning under no bad affect to cultivation soil, in the light of its economical and ecological values. However, some AMF may be diverse from others, the concrete function of AMF on commercial tulip varieties need to explore. Therefore, three different sets of arbuscular mycorrhizal fungi were inoculated into tulip rhizosphere soil, which were set as 4(Diversispora versiformis), 7 (Diversispora spurca) and $1+3+4$ (Rhizophagus intraradias + Funneliformis mosseae + Diversispora versiformis), respectively. The results showed that the activity of most of the measured indices increased, the average root diameter and sucrose content decreased in those three mycorrhizal treatments. Our research provide some theoretical basis for the application of AMF on T.gesneriana ecological cultivation in future.
\end{abstract}

Keywords: Tulip gesneriana, AMF, root architecture, host growth

\section{Introduction}

Fine root usually refers to the root with diameter less than $2 \mathrm{~mm}$, which has a huge absorption surface area. It is an important organ for plants to absorb, transport and store nutrients (Ren et al., 2014, pp. 2535-2543). However, fine roots are greatly affected by biological and abiotic factors, especially the activities of soil microorganisms. Among them, arbuscular mycorrhizal fungi (AMF), as a ubiquitous microorganism in soil, promotes the absorption of water and nutrients by plant roots and the growth of plants. Moreover, AMF colonization further increases the absorption area of fine roots, promotes host growth and development, and promotes the fine roots to play a more important role in plant function, energy flow and material cycle of ecosystem (Jackson et al., 1997, pp.7362-7366; Wu et al.,2011, pp. 273-278). Many studies have shown that mycorrhizal colonization can affect the life span of the host plant root system, and AMF infection can induce significant changes in plant root morphology, which can promote the high branching of plant roots and induce the formation of higher secondary roots and fine roots (Yao et al., 2009, pp. 458-461). At the same time, the mycelial sheath on the surface of plant roots can play a good role in protecting the roots, reducing the damage of soil animals to the root system due to food intake. At the same time, the chemical substances produced can resist the invasion of pathogenic bacteria and enhance the resistance of plant roots (Boyle and Hellenbrand,1991, pp. 1764-1771). At present, many researches mainly focus on the effects of soil and climate factors on the growth and death dynamics of plant roots, while few studies on the effects of AMF on plant root turnover are made.

Tulip belongs to tulip of Liliaceae. It is a world famous bulb flower and an excellent cut flower (Cui et al., 2020, pp. 5-7). The economic value and medicinal value of tulip can not be ignored. Tulip is a well-known flower that is regarded as the national flower by many countries such as Holland, Iran, Turkey and so on. The annual output of tulip in Holland ranks first in the world and has become one of the country's financial resources. The flower and leaf of tulip contain a kind of toxic alkaloid, its physiological function is similar to that of Veratrine Tulin ABC has inhibitory effect on Bacillus subtilis (Ge et al., 2020, pp. 31-35). After passing through cation and anion exchange resin, tulip juice still has antibacterial effect on Staphylococcus aureus. The active components of its stem and leaf alcohol extract contain a variety of amino acids, which has antibacterial effect on Bacillus cereus mycoides. The research on the effect of AMF on Tulip growth is not only improve its commercial quality, but also explore the green-cultivation technique, that is ecological cultivation which will be good at balancing flower quality and environment. In this experiment, tulip was used as the research material, and the effect of AMF on the 
growth and root growth of tulip under different AMF inoculation was studied, which will provide theoretical basis for high quanlity cultivation and offer related experiment data that AMF has good effect on green-cultivation of tulip.

\section{Materials and Methods}

\subsection{Test Materials}

The tulip bulbs were from Zhejiang Hongyue Horticultural Company. AMF was provided by Professor Wu Qiangsheng, Institute of root biology, Yangtze University. The AMF applied in this experiment included Diversispora versiformis, Diversispora spurca, Rhizophagus intraradias and Funneliformis mosseae. Plastic flowerpots (upper diameter $18 \mathrm{~cm}$, bottom diameter $12 \mathrm{~cm}$ height $13 \mathrm{~cm}$ ) were used in the experiment. The soil that was sterilized by high pressure steam $\left(121^{\circ} \mathrm{C}, 2 \mathrm{~h}\right)$ used in this experiment, which was the typical soil types in Jingzhou. Furthermore, the texture was moderate sticky with $\mathrm{pH}$ value from 6.5-7.0, and soil aggregates of $2 \mathrm{~mm}$, $1 \mathrm{~mm}, 0.5 \mathrm{~mm}$ and $0.25 \mathrm{~mm}$ were $22.267 \mathrm{~g}, 3.2 \mathrm{~g}, 5.93 \mathrm{~g}$ and $42.83 \mathrm{~g}$ respectively per $100 \mathrm{~g}$ dry soil.

\subsection{Experimental Design}

In this study, a single factor experiment design was used, with four treatments, namely, Diversispora versiformis, Diversispora spurca, Rhizophagus intraradias + Funneliformis mosseae + Diversispora versiformis, and CK was set as the control group. Each treatment was repeated 4 times, 2 tulip plants were arranged randomly. The infection rate, root indices, carbohydrate, soil phosphatase activity and other indices were measured by three sampling times. The experiment had been carried out in the greenhouse and laboratory of Horticulture and Gardening College of Yangtze University.

\subsection{Determination Index and Methods}

\subsubsection{Determine the Root Infection Rate}

The roots of the samples were randomly selected and cut into $1 \mathrm{~cm}$ long root segments. The roots were fixed in FAA solution (at least 24h at room temperature). Phillips \& Hayman (1970) method was used for staining, decolorization and microscopic examination. Finally, the root infection rate was measured.

\subsubsection{Determination of Glomus in Soil}

The method of Wright (Wright, 2000, pp. 171-177) was used for the determination of glomus in soil with a slight change in dosage. $0.5 \mathrm{~g}$ air-dried soil sample was put into a centrifuge tube with scale, and $4 \mathrm{ml}(\mathrm{pH}=7.0) 20$ $\mathrm{mmol} \cdot \mathrm{L}^{-1}$ sodium citrate extraction agent was added; sterilized for $30 \mathrm{~min}$ at $121^{\circ} \mathrm{C}, 103 \mathrm{kPa}$, and centrifuged at $10000 \mathrm{rpm}$ for $5 \mathrm{~min}$ to obtain the supernatant; $0.25 \mathrm{ml}$ supernatant was added with $2.5 \mathrm{ml}$ Coomassie G-250, and then $0.25 \mathrm{ml} 50 \mathrm{mmol} . \mathrm{L}^{-1}$ sodium citrate extract was added; at the same time, $1 \mathrm{mg} \cdot \mathrm{ml}^{-1}$ bovine serum albumin was accurately prepared. After $5 \mathrm{~min}$ of color development, the OD values of samples and BSA standard solution were determined at $595 \mathrm{~nm}$ with an spectrophotometer (Thermo multiskanfc, USA), and the amount of glomus in each gram of dry soil was calculated.

\subsubsection{Determination of Total Sugar Content}

Anthrone colorimetric method was used and the dosage was slightly modified (Wu et al., 2012, pp. 1554-1556). $0.02 \mathrm{~g}$ dry root samples were treated with water bath, and the volume was $25 \mathrm{ml}$. After finishing those required treatments, the absorbance value was measured at $630 \mathrm{~nm}$.

\subsubsection{Determination of Sucrose Content}

According to the test method of Zhang et al., a slight modification is made (Zhang\& Zhai, 2003, pp. 128-129). 50 $\mathrm{mg}$ dry root sample was weighed at a single time. During the preparation of standard curve, $150 \mu \mathrm{l}$ alcohol extract was taken, $150 \mu \mathrm{l} 2 \mathrm{~mol} / \mathrm{L} \mathrm{NaOH}$ was added, boiled for $5 \mathrm{~min}$ at $100^{\circ} \mathrm{C}$, cooled, and $2.1 \mathrm{ml} 30 \%$ hydrochloric acid and $0.6 \mathrm{ml} 0.1 \%$ resorcinol were added. After all treatments, colorimetric determination was performed at $480 \mathrm{~nm}$.

\subsubsection{Determination of Glucose Content}

Glucose oxidase peroxidase colorimetric method was used with a slight change in dosage (Wang, 1997, pp. 1319). In the preparation of enzyme preparation, $2.5 \mathrm{ml}$ glucose oxidase was added. Take $1.0 \mathrm{ml}$ of enzyme preparation and put it into a $30 \%$ ethanol, stored in brown bottle of $30 \mathrm{me}$ solution rises to balance, add $0.5 \mathrm{ml}$ alcohol extract, shake well, keep temperature for $5 \mathrm{~min}$, add $2 \mathrm{ml} 10 \mathrm{~mol} / \mathrm{L}$ sulfuric acid, and determine the color at $460 \mathrm{~nm}$.

\subsubsection{Determination of Root Architecture Parameters and Other Indicators}

Sampling and testing plant appearance growth was directly measured by electronic scale, ruler and other measuring tools, including leaf length, width, plant height, weight of root ball, and wet weight of root after cleaning; root 
scanner was used to scan root system after each sampling, and root length, diameter, area, volume and root tip counting were analyzed, and finally data processing was carried out.

\subsubsection{Determination Acid Phosphatase in Rhizosphere Soil}

The method was determined by sodium diphenyl phosphate (Zhao \& Jiang, 1986, pp. 12-16).

\subsection{Data Statistics and Analysis}

The ANOVA process of SAS (8.1) software was used to test the difference between the treatments. Duncan's new complex range difference method was used for multiple comparative analysis $(\mathrm{P}<0.05)$. Graphpad prim 8.0 were used for drawing.

\section{Results and Analysis}

\subsection{Effect of AMF on Root Infection Rate and Growth of Tulip}

Under different inoculation treatments, AMF had different effects on root infection rate and growth of tulip. The infection rate of group $1+3+4$ is the highest, reaching $75 \%$, and the group 4 and 7 are also more than $60 \%$ (Tab. 1). As for growth effect, group 7 and $1+3+4$ have significant effects on plant height and bulb weight, but there is nothing positive influence to plant height and weight in group 4 except for ground diameter. In addition, group 7 has a little effect on the ground diameter of tulip (Tab. 2).

Table 1. Effect of AMF on root infection rate (mean \pm standard deviation)

\begin{tabular}{lllll}
\hline Treatments & CK & $\mathbf{4}$ & $\mathbf{7}$ & $\mathbf{1 + 3 + 4}$ \\
\hline Infection rate (\%) & 0 & $64.17 \pm 0.005 \mathrm{~b}$ & $64.47 \pm 0.0304 \mathrm{~b}$ & $75.03 \pm 0.0139 \mathrm{a}$
\end{tabular}

Note: The different letters in the same column indicate significant differences at $\mathrm{P}<0.05$ level. The same below.

Table 2. Effect of AMF on tulip growth (mean \pm standard deviation)

\begin{tabular}{clcl}
\hline Treatments & Plant height $(\mathbf{c m})$ & Ground diameter $(\mathbf{c m})$ & Bulb weight $(\mathbf{g})$ \\
\hline $\mathbf{C K}$ & $38.65 \pm 1.3435 \mathrm{ab}$ & $0.837 \pm 0.0184 \mathrm{c}$ & $18.929 \pm 0.8676 \mathrm{bc}$ \\
$\mathbf{4}$ & $37.65 \pm 1.2728 \mathrm{~b}$ & $0.918 \pm 0.0064 \mathrm{a}$ & $17.544 \pm 4.5017 \mathrm{c}$ \\
$\mathbf{7}$ & $41.98 \pm 2.0082 \mathrm{a}$ & $0.873 \pm 0.0184 \mathrm{bc}$ & $24.320 \pm 0.6693 \mathrm{ab}$ \\
$\mathbf{1 + 3 + 4}$ & $43.18 \pm 3.4295 \mathrm{a}$ & $0.912 \pm 0.0092 \mathrm{ab}$ & $26.581 \pm 4.6507 \mathrm{a}$ \\
\hline
\end{tabular}

\subsection{Effect of AMF on Glomeratin in Tulip Soil}

The effect of inoculating different AMF strains on soil glomalin was different. The content of glomalin in three inoculation treatments was significantly higher than that in the CK. The content of glomus in group 4 and 7 had no significant difference, which was increased by $12 \%$ compared with the CK, while the effect of group $1+3+4$ was the best one, up to $2.14 \mathrm{mg} / \mathrm{g}$ (Figure 1). 


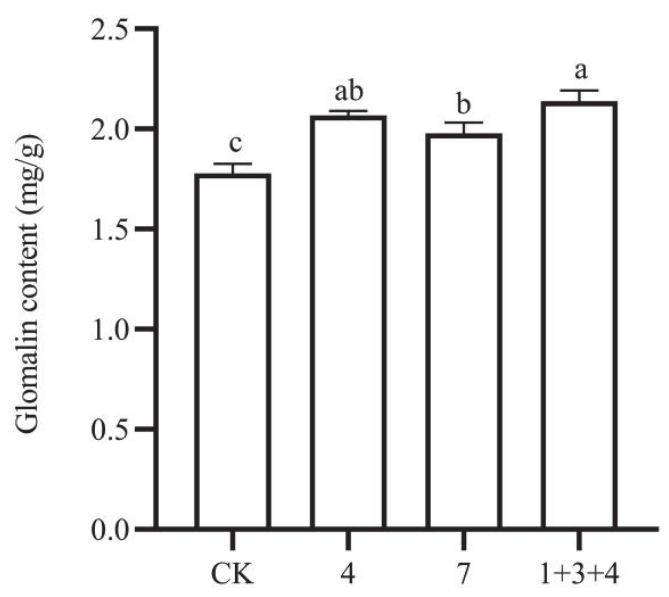

Figure 1. Effect of AMF on glomalin in soil

\subsection{Effect of AMF on the Contents of Total Sugar, Sucrose and Glucose in Tulip}

The results showed that different AMF treatments had different effects on the contents of total sugar, sucrose and glucose in tulip roots (Figure 2). The contents of soluble sugar and glucose in three AMF treatment groups were significantly increased, while sucrose was significantly decreased compared with the $\mathrm{CK}$, and the group $1+3+4$ being the most obvious, with a decrease of $26.3 \%$. The contents of total sugar and glucose in tulip roots of group $1+3+4$ were higher than another two inoculation groups. The effects of those three treatments on the contents of sucrose and glucose were different.

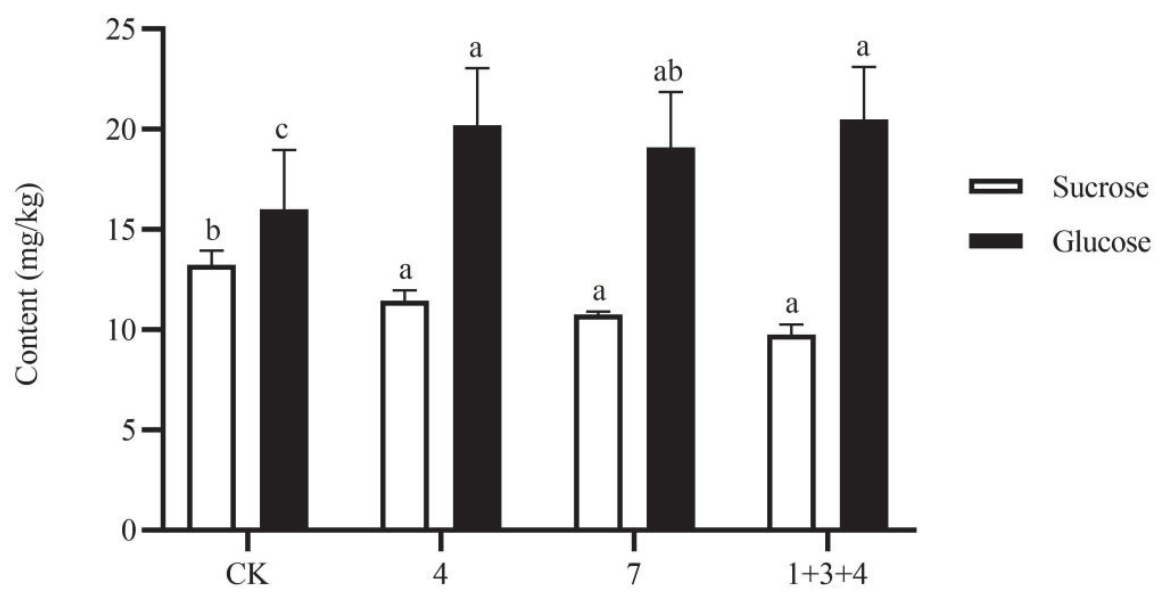

Figure 2. Effect of AMF on the contents of total sugar, sucrose and glucose in tulip

\subsection{Effect of AMF on Root Architecture Parameters of Tulip}

The average root diameter of three groups of AMF treatment was smaller than that of CK group, the most obvious was group 7, the average root diameter of tulip samples was significantly lower than that of other two strains treatment, but there was no significant difference between group 4 and 1+3+4 (Tab. 3). The root length, projected area, surface area and volume of tulip inoculated with AMF were significantly higher than control. The root length, projected area and surface area of group $1+3+4$ were significantly higher than another two treatments, increased by $16.5 \%, 14.1 \%$ and $18.5 \%$, respectively. The root volume of three treatments was $35 \%$ higher than that of control group, and there was no significant difference between group 1+3+4 and 4 (Figure 3). 
Table 3. Effect of AMF on root architecture parameters of tulip (mean \pm standard deviation)

\begin{tabular}{cccc}
\hline Treatments & Length $(\mathbf{c m})$ & Volume $\left(\mathbf{c m}^{\mathbf{3}}\right)$ & Average diameter $(\mathbf{c m})$ \\
\hline $\mathbf{C K}$ & $992.4797 \pm 26.0618 \mathrm{a}$ & $4.369 \pm 0.2998 \mathrm{a}$ & $0.8299 \pm 0.0194 \mathrm{a}$ \\
$\mathbf{4}$ & $1115.5943 \pm 30.7225 \mathrm{a}$ & $7.453 \pm 1.3195 \mathrm{a}$ & $0.7696 \pm 0.0488 \mathrm{a}$ \\
$\mathbf{7}$ & $1069.2454 \pm 12.8211 \mathrm{a}$ & $5.8995 \pm 0.9751 \mathrm{a}$ & $0.7095 \pm 0.094 \mathrm{a}$ \\
$\mathbf{1 + 3 + 4}$ & $1245.1904 \pm 264.2475 \mathrm{a}$ & $7.7035 \pm 3.2138 \mathrm{a}$ & $0.7813 \pm 0.0446 \mathrm{a}$ \\
\hline
\end{tabular}

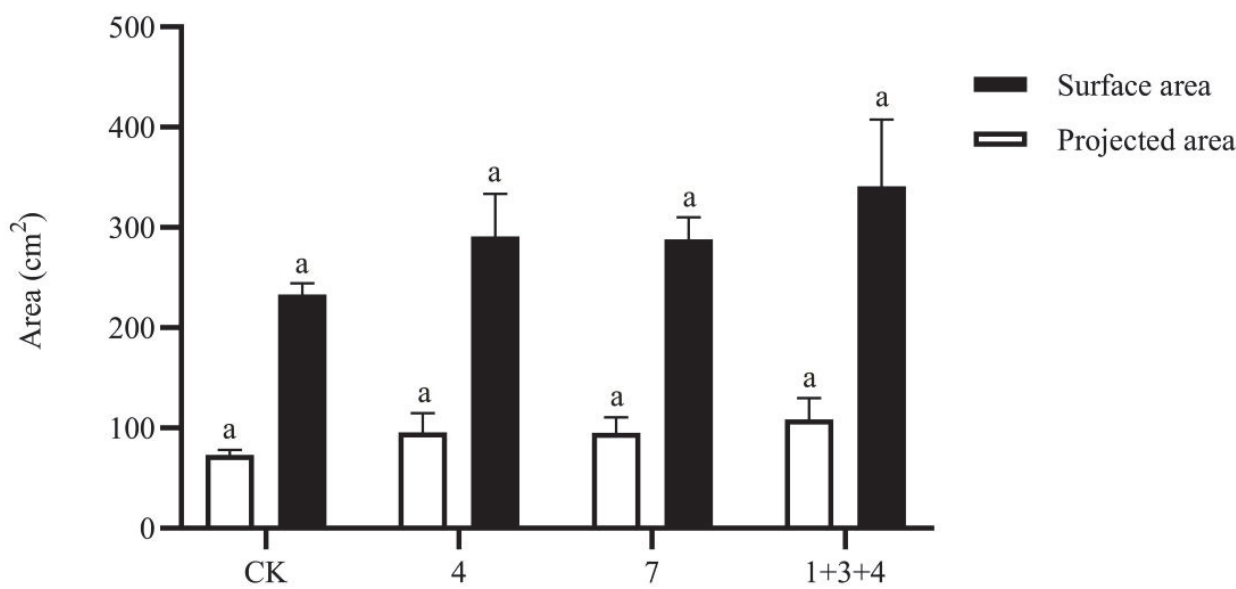

Figure 3. Effect of AMF on root architecture parameters of tulip

The total root length of tulip samples from high to low was $1+3+4>4>7>\mathrm{CK}$ (Figure 4 ). The root length of 0 $1 \mathrm{~cm}$ in AMF treatment group accounted for $85.7 \%-86.9 \%$ of the total root length of tulip, which significantly increased the length of $0-1 \mathrm{~cm}$ root of tulip, and had no significant influence on the length of root system at $1-2 \mathrm{~cm}$, $2-3 \mathrm{~cm}, 3-4 \mathrm{~cm}$ and $>4 \mathrm{~cm}$.
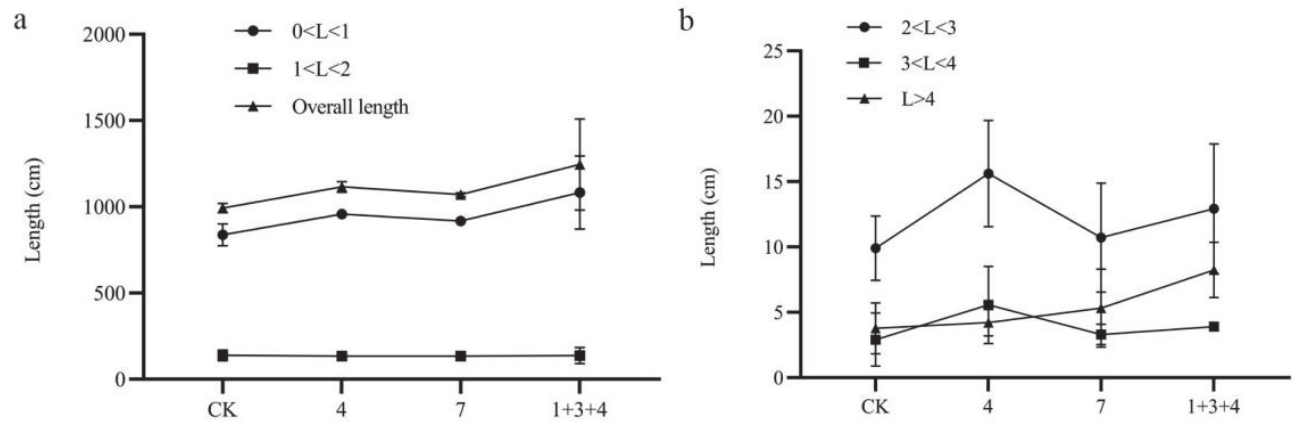

Figure 4. The effects of AMF on the root length of tulip

\subsection{Effect of AMF on Phosphatase Activity of Tulip Soil Under Acid Condition}

Under the same environment, the phosphatase activity of CK group under acid condition was significantly lower than that of three infection groups, the activity of phosphatase between group 7 and 4 had no significant difference under acid condition (Tab. 4), while the phosphatase activity of group $1+3+4$ was significantly higher than that of other two infection groups. The results showed that the activity of acid phosphatase could reflect the infection rate and activity of AMF, and the infection rate was positively correlated with the activity of acid phosphatase. 
Table 4. The relationship between soil phosphatase and infection rate in different AMF under the same habitat

\begin{tabular}{ccccc}
\hline Treatments & $\mathbf{C K}$ & $\mathbf{4}$ & $\mathbf{7}$ & $\mathbf{1 + 3 + 4}$ \\
\hline Soil phosphatase $[\boldsymbol{\mu g} /(\mathbf{g} \cdot \mathbf{h})]$ & 97.32 & 172.57 & 178.43 & 210.46 \\
Infection rate $(\%)$ & 0 & 64.17 & 64.47 & 75.03 \\
\hline
\end{tabular}

\section{Discussion}

AMF can promote the vegetative growth of plant obviously after forming mycorrhizal symbionts with host roots (Chen et al., 2008, pp. 648-653). Root system is an important organ for plants to absorb water and mineral nutrients from soil. Good root system can promote plant growth and development, and root morphology can directly reflect the growth of root system (Willaume \& Pagès, 2011, pp.653-662). AMF inoculation can induce more auxin production in the root system of host plants, thus inducing the formation of lateral root primordial (Kircher \& Schopfer,2012, pp.11217-11221). In this experiment, AMF significantly promoted the growth and morphological formation of tulip roots, and increased length and volume in mycorrhizal plants with a little decreasing in root diameter (Tab. 3). These results indicate that AMF have good effect on forming more fine roots. It is important that mycorrhizal plants keep fine roots architect and good function for providing guarantee for the growth of host by increasing the contact surface between roots and soil, and improving the absorption and utilization efficiency of water and nutrients in soil by roots.

Carbohydrate is one of the important products of plant photosynthesis. It directly participates in the growth and metabolism of plants. AM fungi, as beneficial microorganisms, can help plants absorb nutrients and water, but they need to absorb carbon sources from host plants to maintain their metabolism. Studies have shown that the carbon sources are mainly simple carbohydrates, such as glucose, fructose (Han et al., 2012, pp. 321-342) In this experiment, there were lower sucrose and more glucose tulip in roots inoculated by AMF, which had good effect on keeping host root growth and development by maintaining higher glucose content. Our results was consisted with Zou's research finding (Zou et al., 2014, pp. 1125-1129). This allocation of soluble sugar had better effect for tulip root length, surface area, volume and other related indicators (Tab. 3).

Soil enzyme plays an important guarantee for the smooth progress of various phytochemical processes in the soil environment. Being one of the active organic components in the soil, phosphatase is often regarded as an important standard to estimate the soil fertility by measuring its activity. It was reported that phosphatase affected soil organic components, and phosphatase had a close relationship with the colonization of mycorrhizal fungi (Tarafdar et al., 2015, pp. 279-282). The results of this experiment are consistent with above viewpoint in published literature. As for the relationship between phosphatase and AMF colonization, these are some interesting problem still need to be studied and verified by follow-up experiments.

\section{Conclusion}

In this experiment, AMF colonized successfully in the tulip roots with related high infection rate and had positive effect on plant growth. Furthermore, AMF played good influence on soil property that reflected in more glomalin, better root architecture, glucose in roots with higher soil acid phosphatase in rhizosphere. In conclusion, AMF had a positive impact on tulip growth and its root system architecture. Our research will offer some useful information for higher quality and lower environment effects in tulip cultivation in future.

\section{References}

Boyle, C. D., \& Hellenbrand, K. E. (1991). Assessment of the effect of mycorrhizal fungi on drought tolerance of conifer seedlings. Canadian Journal of Botany, 69(8), 1764-1771. https://doi.org/10.1139/b91224https://doi.org/10.1139/b91-224

Chen, Z. C., Shi, Z. Y., Tian, C. Y., \& Feng, G. (2008). Effects of AM fungi inoculation on growth and mineral nutrient uptake of ephemeral plants. Acta phytoecology, 32(3), 648-653. https://doi.org/10.3773/j.issn.1005$264 \times .2008 .03 .014$

Cui, Y. H., Zhang, Y. Q., \& Xing, G. M., et al. (2020). Research progress of tulip bulb propagation and rejuvenation. Horticulture and Seedling, 9, 5-7. https://doi.org/10.16530/j.cnki.cn21-1574/s.2020.09.003

Ge, B. C., Chen, X. J., \& Jiang, H H. (2020). Optimization of extraction process of total alkaloids from tulip by orthogonal experiment. Journal of Chifeng University (Nat. Sci. Ed.), 36(9), 31-35. https://doi.org/10.13398/j.cnki.issn1673-260x.2020.09.008 
Han, B., Guo, S. R., \& Chao, H. E., et al. (2012). Effects of arbuscular mycorrhiza fungi (AMF) on the plant growth, fruit yield, and fruit quality of cucumber under salt stress. Chinese Journal of Applied Ecology, 23(1), 321-342. https://doi.org/10.13287/j.1001-9332.2012.0021

Jackson, R. B., Mooney, H. A., \& Schulze, E. D. (1997). A global budget for fine root biomass, surface area, and nutrient contents. Proceedings of the National Academy of Sciences, 94(14), 7362-7366. https://doi.org/10.1073/pnas.94.14.7362

Kircher, S., \& Schopfer, P. (2012). Photosynthetic sucrose acts as cotyledon-derived long-distance signal to control root growth during early seedling development in Arabidopsis. Proceedings of the National Academy of Sciences of the United States of America, 109(28), 11217-11221. https://doi.org/10.1073/pnas.1203746109

Ren, A., Narkes, W., \& Lu, W. H. et al. (2014). Effect of the Arbuscular Mycorrhizal Fungi on the Dynamic Characteristics of Fine Root Growth and Biomass of Alfalfa. Acta Botanica Sinica, 34(12), 2535-2543. https://doi.org/10.7606/j.issn.1000-4025.2014.12.2535

Tarafdar, J. C., Yadav, R. S., \& Meena, S. C. (2015). Comparative efficiency of acid phosphatase originated from plant and fungal sources. Journal of Plant Nutrition and Soil Science, 64(3), 279-282. https://doi.org/10.1002/1522-2624(200106)164:3<279::AID-JPLN279>3.0.CO;2-L

Wang, J. B. (1997). Histochemical dynamics of seed germination of Crotalaria cristata. Acta botany Sinica, 17(L), 13-19. https://doi.org/cnki:sun:dnyx.0.1997-01-002

Willaume, M., \& Pagès, L. (2011). Correlated responses of root growth and sugar concentrations to various defoliation treatments and rhythmic shoot growth in oak tree seedlings (Quercus pubescens). Annals of Botany, 107(4), 653-662. https://doi.org/10.1093/aob/mcq270https://doi.org/10.1093/aob/mcq270

Wright, S.F. (2000). A fluorescent antibody assay for hyphae and glomalin from arbuscular mycorrhizal fungi. Plant and Soil, 226, 171-177. https://doi.org/10.1023/A:1026428300172

Wu, C. B., Tian, L. S., Wu, J. Y., \& Chen, F., et al. (2012). Processing technology of Artemisia selengensis tea and changes of flavonoids and polysaccharides active components. Modern Food Science and Technology, 28(11), 1554-1556. https://doi.org/10.13982/j.mfst.1673-9078.2012.11.038

Wu, Q. S., Zou, Y. N., \& He, X. H., et al. (2011). Arbuscular mycorrhizal fungi can alter some root characters and physiological status in trifoliate orange (Poncirus trifoliata L. Raf.) seedlings. Plant Growth Regulation, 65(2), 273-278. https://doi.org/10.1007/s10725-011-9598-6

Yao, Q., Wang, L. R., \& Zhu, H. H. et al. (2009). Effect of arbuscular mycorrhizal fungal inoculation on root system architecture of trifoliate orange (Poncirus trifoliata, L. Raf.) seedlings. Scientia Horticulturae, 121(4), 458-461. https://doi.org/10.1016/j.scienta.2009.03.013

Zhang, Z. L., \& Zhai, W. Q. (2003). Experimental guidance of plant physiology (Ed. 3). Higher education press (pp128-129), Beijing,.. China: China Higher Education Press.

Zhao, L. P., \& Jiang, Y. (1986). Discussion on Determination of soil phosphatase activity. Soil Bulletin, (3), 12-16. https://doi.org/10.19336/j.cnki.trtb.1986.03.013

Zou, Y. N., Wu, Q. S., Li, Y., \& Huang, Y. M. (2014). Effects of arbuscular mycorrhizal fungi on root system morphology and sucrose and glucose contents of Poncirus trifoliata. Chinese Journal of Applied Ecology, 25(4), 1125-1129. https://doi.org/10.13287/j.1001-9332.20140210.0077https://doi.org/10.13287/j.10019332.20140210.0077

\section{Copyrights}

Copyright for this article is retained by the author(s), with first publication rights granted to the journal.

This is an open-access article distributed under the terms and conditions of the Creative Commons Attribution license (http://creativecommons.org/licenses/by/4.0/). 